\title{
Your Appels to Intuition Have No Power Here!
}

\author{
Moti Mizrahi
}

\begin{abstract}
In this paper, I argue that appeals to intuition in Analytic Philosophy are not compelling arguments because intuitions are not the sort of thing that has the power to rationally persuade other professional analytic philosophers. This conclusion follows from reasonable premises about the goal of Analytic Philosophy, which is rational persuasion by means of arguments, and the requirement that evidence for and/or against philosophical theses used by professional analytic philosophers be public (or transparent) in order to have the power to rationally persuade other professional analytic philosophers. Since intuitions are not public (or transparent) evidence, it follows that appeals to intuition are not compelling arguments for and/or against philosophical theses because they lack the power to rationally persuade other professional analytic philosophers.
\end{abstract}

Keywords: Analytic Philosophy; appeal to intuition; argument; metaphilosophy; philosophical methodology

\section{Introduction}

There is an ongoing methodological debate in contemporary Analytic Philosophy ${ }^{1}$ concerning the use of intuitions as evidence (see, e.g., Hannon 2018). Participants in this debate concern themselves with 'questions like 'Are intuitions that $p$ used as evidence that $p$ ?' and 'Are intuitions that $p$ evidence that p?"” (Andow 2016, p. 244). Some analytic philosophers, like Chalmers (2014, p. 535), "find it fairly obvious that many philosophers, including [himself], appeal to intuitions," whereas others, like Deutsch (2015), deny that intuitions play an evidential role in Analytic Philosophy. Rather than ask, "[D]o philosophers use intuitions as evidence, or take intuitions to be evidence?" (Climenhaga 2018, p. 72), I would like to ask a somewhat different question in this paper; that is, are intuitions good (or compelling) evidence for and/or against philosophical theses?

In this paper, I develop a new argument to the effect that intuitions are not good (or compelling) evidence for and/or against philosophical theses. The focus of this paper is the use of intuitions as evidence in Analytic Philosophy, or more precisely, the use of appeals to intuition as a philosophical methodology or style of argument, not the ontology or psychology of intuitions (De Cruz 2015). An appeal to intuition is an argument that proceeds from the premise that $S$ intuits that $p$ to the conclusion that $p .^{2}$ In Analytic Philosophy, such arguments are usually made in the context of hypothetical cases, which is why this style of argument is also known as the "method of cases" (see, e.g., Baz 2016a, 2016b), "which consists in eliciting an intuitive

\footnotetext{
${ }^{1}$ According to Schwitzgebel et al. (2018, p. 22), “Mainstream Anglophone philosophy is vague-boundaried and nebulous. However, it can be characterized well enough to permit sociological examination. Participants in this group are philosophers who write primarily in English (regardless of their native language); publish in Englishlanguage academic journals that are widely regarded as prestigious by other English-language philosophers, such as Philosophical Review and Ethics; belong to PhD-granting departments that are ranked in the Philosophical Gourmet Report, or have close scholarly ties to people in those departments; and are highly cited in the Stanford Encyclopedia of Philosophy and in prestigious English-language journals."

${ }^{2}$ According to Levy $(2013$, p. 382), "to intuit that $p$ is for one to have a relatively forceful impression that $p$ seems to be the case.” See Climenhaga (2018, pp. 69-70).
} 
judgment as a response to a described hypothetical case" (Cohnitz and Haukioja 2015, pp. 617618). According to Mizrahi (2014, p. 186), the "method of cases" consists of the following steps:

Step 1: Intuition Pump. In this step, $S$ considers a hypothetical case $C$ that is supposed to elicit an intuition (i.e., an intellectual seeming or intuitive appearance) $I$.

Step 2: Appeal to Intuition. In this step, $S$ uses the content of $I$ (whose justifier is that it intellectually seems/intuitively appears to $S$ that $I$ is the case in $C$ ) as a premise in an argument for or against a philosophical theory $T .^{3}$

Likewise, Suhler (2019, p. 829) summarizes the "method of cases" as follows:

1. Propose a theory setting out criteria for some phenomenon of philosophical interest (e.g., knowledge is justified true belief).

2. Test whether the theory's criteria yield verdicts that match our intuitions in particular cases, including imaginary cases (thought experiments) that we devise for the express purpose of testing the theory.

3. If the theory's verdict matches up with our intuitions about a particular case, this is evidence for the theory's adequacy. If the theory's verdict fails to match up with our intuitions about a particular case, this is evidence against the theory's adequacy; if such a counterexample is encountered, one (generally) should revise the theory and repeat the process. $^{4}$

In this paper, I focus on appeals to intuition in particular, i.e., Step 2 in Mizrahi's (2014, p. 189) description and Step 2 in Suhler's (2019, p. 829) description of the "method of cases." For any appeal to what seems to one to be the case as evidence that what seems to one to be the case is in fact the case, whether in response to a hypothetical case or not, is an appeal to intuition. That is (Ashton and Mizrahi 2018, p. 602):

It seems to $S$ that $p$.

$\therefore p .^{5}$

Accordingly, appeals to intuition are arguments in which the evidence for $p$ is supposed to consist in $S$ finding $p$ intuitive. Bach $(1984$, p. 38) labels this kind of reasoning "default reasoning," which is based on what he calls the "take-for-granted rule": "If it seems to me that $p$, then infer that $p$, provided no reason to the contrary occurs to me" (Bach 1984, p. 43). ${ }^{6}$ For example, when Jackson (1982, p. 130) writes, "It seems just obvious that [Mary] will learn something about the world and our visual experience of it" (emphasis added), he appeals to his own intuition that Mary will learn something new upon exiting the black and white room. He then uses the content of his intuition, namely, <Mary learns something about the world when she leaves the black and white room> as evidence that Mary does in fact learn something new upon

\footnotetext{
${ }^{3}$ See also Machery (2017, Ch. 1).

${ }^{4}$ See also Baz (2016a, p. 107).

${ }^{5}$ According to Williamson (2007, p. 214), "When contemporary analytic philosophers run out of arguments, they appeal to intuitions." However, an appeal to intuition is itself a type of argument. When one appeals to intuition, one's conclusion that $p$ is supposed to be supported by the fact that one has a "relatively forceful impression that $p$ seems to be the case" (Levy 2013, p. 382). See also Mizrahi (2015, pp. 142-143).

${ }^{6}$ Cf. Huemer's (2007, p. 30) Phenomenal Conservatism: "If it seems to $S$ that $p$, then, in the absence of defeaters, $S$ thereby has at least some degree of justification for believing that $p$." See Moretti (2015).
} 
her release, which he then uses as a premise in his argument against physicalism (see Mizrahi 2014, pp. 184-185). The question for present purposes, then, is whether the "take-for-granted" rule is a good philosophical methodology. Are appeals to intuition compelling arguments, i.e., the sort of arguments that proceed from premises that have the "power to compel agreement" (Chalmers 2015, p. 25) among professional analytic philosophers? To put it another way, are appeals to intuition the sort of arguments that have the power to rationally persuade other professional analytic philosophers? In this paper, when I talk about appeals to intuition in Analytic Philosophy, I mean arguments with " $S$ intuits that $p$ " (or "It seems to $S$ that $p$ ") as a premise and " $p$ " as the conclusion. ${ }^{7}$

In what follows, I argue that appeals to intuition in Analytic Philosophy are not compelling arguments because intuitions are not the sort of thing that has the power to rationally persuade other professional analytic philosophers. My overall argument consists of three parts. The conclusion of the first part is that the goal of Analytic Philosophy is "to compel agreement" (Chalmers 2015, p. 25) or rational persuasion. I sketch this part of my overall argument in Section 2. The conclusion of the second part is that evidence for and/or against philosophical theses must be public (or transparent) in order "to compel agreement" (Chalmers 2015, p. 25) or rationally persuade other professional analytic philosophers. I sketch this part of my overall argument in Section 3. The conclusion of the third part is that intuitions are not the sort of thing that has the power "to compel agreement" (Chalmers 2015, p. 25) or rationally persuade other professional analytic philosophers. I sketch this part of my overall argument in Section 4. In Section 5, I anticipate and respond to several objections. If my overall argument is sound, then appeals to intuition are not compelling arguments for and/or against philosophical theses, since intuitions lack the power "to compel agreement" (Chalmers 2015, p. 25) or rationally persuade other professional analytic philosophers. ${ }^{8}$

\section{The Heart of Analytic Philosophy is Argument}

Introductory texts tell students that the heart of philosophy is argumentation. For example, according to Lacewing (2014, p. 7), "At the heart of philosophy is philosophical argument." In practice, too, philosophers generally agree that doing philosophy professionally (as opposed to amateurishly) means advancing arguments for and/or against philosophical theses. As Verene (1989, p. 141) writes:

\footnotetext{
7 See Mizrahi (2014, p. 186), Baz (2016a, p. 107), and Suhler (2019, p. 829). As mentioned above, some (e.g., Deutsch 2015) deny that professional analytic philosophers make such arguments in philosophical practice. I will say more about that in Section 5. Even if professional analytic philosophers do not appeal to intuitions in philosophical practice, it might still be useful to have an argument that shows that appeals to intuition are bad arguments. Cf. Molyneux (2014).

${ }^{8}$ Molyneux (2014, p. 441) distinguishes between "descriptive evidentialism," which is the view that intuitions are treated as evidence in Analytic Philosophy, and "normative evidentialism," which is the view that intuitions should be treated as evidence in Analytic Philosophy. As mentioned in footnote 7, even if professional analytic philosophers do not appeal to intuitions in philosophical practice, it might still be useful to have an argument that shows that appeals to intuition are bad arguments. In that respect, it is also worth mentioning that professional analytic philosophers could be using intuitions is some non-evidential ways (see, e.g., Ramsey 2019).

${ }^{9}$ See also Martin (2017), Harrell (2016), and Taylor (1995).
} 
That philosophy essentially depends on argument is taken as such common knowledge that to dispute it seems simply to abandon philosophy for some other form of thinking (emphasis added).

Similarly, Bruce and Barbone (2011, p. 1) express the point about the essence of philosophy being argumentation as follows: "Show me the argument' is the battle cry for philosophers." Moreover, the conviction that the heart of philosophy is argument also plays a role in philosophical argumentation itself. For instance, Cohen (2004, p. 117) argues that, "If argument is the heart of philosophy, then metaphor is its life-giving blood."

When it comes to Analytic Philosophy in particular, the emphasis on argumentation is even more pronounced, although "emphasis on argumentation has always been central — and self-consciously so - in philosophy" (Beaney 2013, p. 24). According to the manifesto of the European Society for Analytic Philosophy (ESAP), "Analytic philosophy is characterized above all by the goal of clarity, the insistence on explicit argumentation in philosophy, and the demand that any view expressed be exposed to the rigours of critical evaluation and discussion by peers" (quoted in Dainton and Robinson 2014, p. xii). As Beaney (2013, p. 24) puts it, "analytic philosophy is widely regarded as placing emphasis on argumentation, clarity, and rigour." Likewise, Soames (2003, p. xiii) writes that analytic philosophers are committed "to the ideals of clarity, rigor, and argumentation."

Now, if philosophy in general, and Analytic Philosophy in particular, are all about argumentation, i.e., if doing analytic philosophy professionally essentially means putting forth arguments for and/or against philosophical theses, then the next question is this: what do professional analytic philosophers aim to accomplish when they advance arguments for and/or against philosophical theses? According to argumentation theorists, the aim of argumentation is rational persuasion. When arguers advance arguments, they aim to rationally persuade their audience. As Johnson (2000, p. 168) writes:

An argument is a type of discourse or text---the distillate of the practice of argumentation - in which the arguer seeks to persuade the Other(s) of the truth of a thesis by producing the reasons that support it (emphasis added). ${ }^{10}$

In other words, when we argue we aim to provide (good) reasons or evidence in an attempt to convince others to believe what we believe to be true. For reasons or evidence is "that which justifies belief" (Achinstein 2001, p. 25) and "[a]t the end of reasons comes persuasion" (Wittgenstein 1969, §612). ${ }^{11}$ Persuasion here means rational persuasion, or "persuasion by [good] reasons" (Bermejo-Luque 2011, p. 29), i.e., to persuade by offering (good) reasons or (compelling) evidence in support of what one believes to be the case. As Govier (2010, p. 2) writes, "When we use arguments in the sense of offering reasons for our beliefs, we are responding to controversies by attempting rational persuasion." Without rational persuasion at the end of reasons, two arguers would be like the two people in Monty Python's argument clinic, exchanging "Yes, it is" and "No, it isn't" back and forth with no end in sight.

\footnotetext{
${ }^{10}$ See also Govier and Hoaglund (1999, p. 99).

${ }^{11}$ See also Mitova (2017, Ch. 6) and Trafford (2017, Ch. 4).
} 
Putting these two claims together, namely, that the essence of Analytic Philosophy is argumentation and that the goal of argumentation is rational persuasion, we can sketch the following argument concerning the goal of Analytic Philosophy.

(1) The essence of Analytic Philosophy is argumentation.

(2) The goal of argumentation is rational persuasion.

Therefore,

(3) The goal of Analytic Philosophy is rational persuasion.

This argument is the first part of my overall argument. Let me try to alleviate a few concerns at the outset. One might think that the goal of Analytic Philosophy is knowledge, truth, or understanding, so it is important to note that to say that the goal of Analytic Philosophy is rational persuasion is not incompatible with saying that the goal of Analytic Philosophy is knowledge, truth, or understanding. This is because the means of getting to knowledge, truth, or understanding are arguments. How else would professional analytic philosophers know that they have discovered truth, attained knowledge, or gained understanding in Analytic Philosophy if not by means of philosophical argumentation? Indeed, in any academic discipline or professional field of inquiry, including Analytic Philosophy, practitioners take a thesis, hypothesis, or theory to be true, count as knowledge, or provide understanding just in case it can be supported by good reasons or compelling evidence. As Bermejo-Luque (2011, p. 118) writes, "Argumentation is also a means to produce 'rational persuasion', that is, to produce persuasion prompted by reasons."

One might also worry that the rational persuasion of others is not essential to argumentation, so it is important to note that, as in any academic discipline or professional field of inquiry, professional analytic philosophers try to rationally persuade peers that their theses are worthy of presentation in conferences, publication in journals and/or books, and citation by other practitioners in the field. They do so by subjecting their theses, presented in the form of argumentative papers, to peer review whenever they submit their papers to conferences and/or journals. In other words, in Analytic Philosophy, as in any academic discipline or professional field of inquiry, practitioners aim to rationally persuade their peers to believe their theses by advancing arguments in support of those theses. In Analytic Philosophy, as in any academic discipline or professional field of inquiry, it is not enough that one is rationally persuaded by one's own arguments; rather, one has to persuade one's peers by offering (good) reasons or (compelling) evidence in support of what one believes to be the case. Of course, professional analytic philosophers do not have to rationally persuade every person on the street that their philosophical theses are worthy of belief (although they could try to do that, without risking death by hemlock, one would hope). ${ }^{12}$ Rather, they have to rationally persuade some of their academic peers, such as reviewers and editors, at academic conferences where they present their

\footnotetext{
12 Some think that professional analytic philosophers should engage in so-called "public philosophy." The American Philosophical Association has a Public Philosophy Committee whose charge is "to find and create opportunities to demonstrate the personal value and social usefulness of philosophy" (https://www.apaonline.org/group/public). If professional analytic philosophers are required to do public philosophy in addition to academic philosophy, then the demand to appeal to evidence that has the power to rationally persuade others would only be stronger, not weaker. For, in that case, "others" would include not only professional analytic philosophers but also laypeople.
} 
scholarly work or when they submit papers to be considered for publication in academic journals.

In fact, that is precisely what I am doing right now. Having presented this paper at academic conferences, I am trying to rationally persuade you, my academic peer and colleague, that my thesis, namely, that appeals to intuition in Analytic Philosophy are not compelling arguments because intuitions are not the sort of thing that has the power to rationally persuade other professional analytic philosophers, is worthy of consideration. It is not enough that I am rationally persuaded by my own (good) reasons or (compelling) evidence for this thesis. Rather, I have to rationally persuade the anonymous reviewers for the academic journal to which I have submitted my paper. And I attempt to do so by giving (what I take to be) good reasons or compelling evidence for it, given that rational persuasion is "using an argument where all the premises are accepted by the respondent [e.g., a reader, a reviewer, a referee, an editor, etc.] and where the argument is rationally binding by some standard of structural correctness of the argument from the premises to the conclusion" (Walton 2005, p. 126).

With (3), i.e., that the goal of Analytic Philosophy is rational persuasion, in hand, we can now proceed to the second part of my overall argument. Using (3), I argue that "that which justifies belief" (Achinstein 2001, p. 25), i.e., (good) reasons or (compelling) evidence, must be public (or transparent) in order to have the power to rationally persuade other professional analytic philosophers.

\section{Philosophical evidence must be public to be rationally persuasive}

In the previous section, I argued that the goal of Analytic Philosophy is rational persuasion. Professional analytic philosophers try to persuade their peers by providing (good) reasons or (compelling) evidence in support of their philosophical theses. For such reasons or evidence to have the power to rationally persuade other professional analytic philosophers, however, they must be able to have an effect not only on oneself but also on one's academic peers. As Peirce (1877, p. 10) writes:

Our external permanency would not be external, in our sense, if it was restricted in its influence to one individual. It must be something which affects, or might affect, every man.

In other words, (good) reasons or (compelling) evidence must have the power "to compel agreement" (Chalmers 2015, p. 25) or to rationally persuade others; otherwise, they would be useless as far as attaining the goal of argumentation is concerned. To attain the goal of philosophical argumentation, which is rational persuasion, philosophical reasons or evidence must be something that affects, or might affect, other professional analytic philosophers; in other words, philosophical reasons or evidence must be public. If philosophical evidence is not public, it would not have the power to rationally persuade professional analytic philosophers other than oneself, and thus the goal of philosophical argumentation could never be attained. Given that the goal of philosophical argumentation is rational persuasion, philosophical evidence must be public in order to have the power to rationally persuade professional analytic philosophers other than oneself. 
From the claim that the goal of Analytic Philosophy is rational persuasion, then, it follows that philosophical evidence must be public; otherwise, it would not have the power "to compel agreement" (Chalmers 2015, p. 25) or to rationally persuade other professional analytic philosophers and the goal of Analytic Philosophy could never be achieved. That is:

(3) The goal of Analytic Philosophy is rational persuasion.

(4) If the goal of Analytic Philosophy is rational persuasion, then philosophical evidence must be public in order to have the power to rationally persuade other professional analytic philosophers.

Therefore,

(5) Philosophical evidence must be public in order to have the power to rationally persuade other professional analytic philosophers.

This argument is the second part of my overall argument. Again, let me try to alleviate a few concerns at the outset. I have characterized public reasons or evidence in terms of the power to have an effect on others, specifically, the power to "to compel agreement" (Chalmers 2015, p. 25 ) or to rationally persuade other professional analytic philosophers. The term 'public' is used in many ways, so it can be misinterpreted. To avoid misinterpretations, I would like to point out that nothing hangs on the term 'public' per se. The same point can be made using the term 'transparent'. For instance, on Dutilh Novaes' (2015, p. 601) dialogical account of the normativity of logic, "the didactic, cooperative component is [...] represented by the methodological desideratum that a deductive argument be perspicuous and explanatory, i.e., that each individual step be persuasive and transparent" (emphasis added). Similarly, for philosophical reasons or evidence to be rationally persuasive, they must be transparent (or public). And for appeals to intuition in Analytic Philosophy to be compelling arguments, i.e., the sort of arguments that can rationally persuade other professional analytic philosophers, each step in those arguments must be persuasive and transparent. ${ }^{13}$

With (5), i.e., that philosophical evidence must be public (or transparent) in order to have the power "to compel agreement" (Chalmers 2015, p. 25) or to rationally persuade other professional analytic philosophers, in hand, we can now proceed to the third part of my overall argument. Using (5), I argue that intuitions are not the sort of thing that has the power to rationally persuade other professional analytic philosophers. More explicitly, intuitions are not public (or transparent) evidence, and thus they lack the power to rationally persuade other professional analytic philosophers.

\section{Intuitions lack the power to rationally persuade other professional analytic philosophers}

In the previous section, I argued that philosophical reasons or evidence must be public (or transparent) in order to have the power to rationally persuade other professional analytic philosophers, given that the goal of Analytic Philosophy is rational persuasion by means of arguments. Evidence that is not public (or transparent) can have no effect on others, and hence is not the sort of thing that can rationally persuade others. In other words, arguments that appeal to

\footnotetext{
${ }^{13}$ On the publicity, transparency, or intersubjectivity of evidence, see Kelly (2016).
} 
evidence that is not public (or transparent) cannot be compelling arguments because such evidence lacks the power to rationally persuade one's academic peers. When said about evidence or arguments, "compelling" means "inspiring conviction," or possessing the power "to compel agreement" (Chalmers 2015, p. 25). Therefore, evidence cannot be compelling if it lacks the power to inspire conviction in others. Accordingly, arguments that appeal to evidence that is not public (or transparent) are arguments that appeal to evidence that lacks the power to rationally persuade others, and thus are not compelling arguments.

Now, there is a debate in Analytic Philosophy as to the nature of intuitions. ${ }^{14}$ Nevertheless, most philosophers agree that intuitions are psychological or mental states. As Cappelen (2012, p. 8) writes, "Many philosophers [...] take 'intuition' to denote a psychological (mental) state or event." Likewise, according to Climenhaga (2018, p. 70), "intuitions [are] mental states that we find ourselves in when considering particular propositions. [O]ne has an intuition that $\mathrm{P}$ [when] it seems to one that P." 15 If "one has an intuition that $\mathrm{P}$ [when] it seems to one that P" (Climenhaga 2018, p. 70), then intuitions are personal and private mental states. In other words, intuition is not a public (or transparent) source of evidence. As such, intuitions are not "something which affects, or might affect, every man" (Peirce 1877, p. 10). Rather, an intuition is something that affects, or might affect, only the person who has it. That is, if I have the intuition that $p$, then that intuition can only have an effect on me insofar as I have it. You might have an intuition that $p$ as well. But your intuition is yours and my intuition is mine; they are distinct mental states, even if the content of our intuitions, namely, $p$, might be the same. When I appeal to intuition, I use my intuition that $p$ as evidence for $p$, whereas when you appeal to intuition, you use your intuition that $p$ as evidence for $p$. Although we are both arguing for $p$ by appeal to intuition, our evidence is not the same: my evidence is my intuition that $p$, whereas your evidence is your intuition that $p$. Clearly, your intuition that $p$ and my intuition that $p$ are distinct because the former is in your head, whereas the latter is in my head.

Now, if philosophical evidence must be public (or transparent) in order to rationally persuade other professional analytic philosophers, but intuitions are not public (or transparent) evidence, then it follows that intuitions are not the sort of thing that has the power to rationally persuade other professional analytic philosophers. In other words, appeals to intuition are not compelling arguments because intuitions are not the sort of evidence for and/or against philosophical theses that has the power to rationally persuade other professional analytic philosophers. That is:

(5) Philosophical evidence for and/or against philosophical theses must be public (or transparent) in order to have the power to rationally persuade other professional analytic philosophers.

\footnotetext{
${ }^{14}$ See, e.g., Booth and Rowbottom (2014).

${ }^{15}$ Some might think that intuitions are not mental states but rather applications of concepts. For example, when one intuits that $S$ doesn't know that $p$ in a Gettier case, one applies one's concept of knowledge to a Gettier case. As Cummins (1998, p. 125) argues, however, this would render intuitions "epistemologically useless" as a method of philosophical inquiry. For intuitions are supposed to provide evidence for or against philosophical theories about concepts, such as knowledge. But if one already has a concept of knowledge that one can apply to cases successfully, then one has no need for a philosophical analysis of knowledge. As Cummins (1998, p. 124) writes, "If you know enough to start fixing problems with philosophical intuition, you already know enough to get along without it."
} 
(6) Intuitions are not public (or transparent) evidence.

Therefore,

(7) Intuitions lack the power to rationally persuade other professional analytic philosophers.

This argument is the third part of my overall argument. Again, let me try to alleviate any concerns about the notion of publicity (or transparency). For a similar argument can be made by appealing to what Williamson (2007, p. 210) calls "Evidence Neutrality," which is the principle that, "whether a proposition constitutes evidence is in principle uncontentiously decidable, in the sense that a community of inquirers can always in principle achieve common knowledge as to whether any given proposition constitutes evidence for the inquiry." 16 Insofar as the academic community of professional analytic philosophers is concerned, namely, Analytic Philosophy, common knowledge as to whether any given intuitive judgment constitutes evidence for and/or against a philosophical thesis is rarely, if ever, achieved. ${ }^{17}$ Now, if evidence should serve as a neutral arbiter for a community of inquirers, but intuitions cannot serve as neutral arbiters for Analytic Philosophy, then it follows that intuitions are not compelling evidence in Analytic Philosophy. In other words, intuition is not a source of evidence that can serve as a neutral arbiter in Analytic Philosophy.

\section{More objections and replies}

In the previous section, I argued that appeals to intuition are not compelling arguments in Analytic Philosophy because intuitions are not the sort of thing that has the power to rationally persuade other professional analytic philosophers. In this section, I anticipate and reply to additional objections to my overall argument.

\subsection{Professional analytic philosophers don't appeal to intuitions in philosophical practice!}

The first objection states that intuitions are not used as evidence in Analytic Philosophy, so there is no need to show, as I have tried in this paper, that appeals to intuition in Analytic Philosophy are not compelling arguments. Following the work of Cappelen (2012), other philosophers have also argued that professional analytic philosophers do not use intuitions as evidence in philosophical practice. Nado (2016b, p. 782) calls these philosophers, such as Cappelen (2012) and Deutsch (2015), ${ }^{18}$ "the intuition deniers," since they argue that "philosophers generally don't employ intuitions as evidence in the first place."19

\footnotetext{
${ }^{16}$ On evidence as neutral arbiter, see Kelly (2016).

${ }^{17}$ See Prinz, (2006, p. 39): "we can move beyond the typical intuition mongering in philosophy and use empirical findings to help adjudicate an otherwise interminable philosophical debate."

${ }^{18}$ Deutsch argues that professional analytic philosophers evaluate hypothetical cases by using arguments rather than intuitions. Pace Deutsch, Wysocki (2017) presents the results of an experimental study according to which exposure to arguments about Gettier cases does not significantly influence participants' responses. Even if Deutsch is right that professional analytic philosophers evaluate hypothetical cases by using arguments, it doesn't necessarily follow that philosophers do not use intuitions as evidence. For, insofar as appeals to intuition are a type of argument, it can be true both that philosophers evaluate hypothetical cases by using arguments and that they appeal to intuition.

${ }^{19}$ Climenhaga (2018) argues that intuitions are used as evidence in Analytic Philosophy.
} 
As Nado's (2016b) discussion of the arguments put forth by "the intuition deniers" makes clear, the strategy of those intuition deniers is to define 'intuition' in such a way that it turns out that professional analytic philosophers do not use such things as evidence. As Nado (2016b, p. 798) points out, however, the result of this strategy is "a misleading and oversimplistic characterization of philosophical practice." ${ }^{20}$ For it does not matter how we define the term 'intuition' (Devitt 2015). ${ }^{21}$ What matters is that, in practice, professional analytic philosophers appeal to what seems true to them, and the question is whether such appeals to intuition are compelling arguments in philosophical practice. Arvan (2017, pp. 96-97) makes this point in a review of a collection of essays on experimental philosophy and philosophical methodology edited by Nado (2016c):

The ultimately relevant philosophical question is not whether philosophers invoke 'intuitions' but whether the kinds of premises philosophers appeal to-whatever we call them - are epistemically suitable foundations for philosophical argumentation.

If my overall argument is sound, then intuitions are not epistemically suitable starting points for philosophical argumentation, since they are not the sort of thing that can help us achieve the goal of Analytic Philosophy, which is to rationally persuade other professional analytic philosophers by means of arguments.

To illustrate, consider the following example, which is discussed in Ashton and Mizrahi (2018, p. 604) as well:

The nerve of Mr. Bennett's argument is that if A results from your not doing B, then A results from whatever you do instead of doing B. While there may be much to be said for this view, still it does not seem right on the face of it (Anscombe 1966; emphasis added).

In this case, Anscombe tells us that Bennett's view seems false to her without providing any reasons or evidence for the claim that Bennett's view is false other than the fact that it seems false to her. If anything counts as an appeal to intuition in philosophical practice, this surely does. That Anscombe has the intuition that Bennett's view is false, however, does nothing at all to rationally persuade me (or any other professional analytic philosopher, for that matter) that Bennett's view is false. In other words, an argument that appeals to Anscombe's intuition that Bennett's view is false in support of the conclusion that Bennett's view is false is not a compelling argument. That is:

P: It seems to me (namely, Anscombe) that Bennett's view is false.

Therefore,

C: Bennett's view is false.

The premise of this argument $(\mathrm{P})$ gives me no reason whatsoever to believe that the conclusion (C) is true or probably true. So, this argument, which is an appeal to intuition, is not a compelling argument.

\footnotetext{
${ }^{20}$ See Devitt (2015).

${ }^{21}$ See Chalmers (2014), for whom, "there is a minimal construal of intuitions as judgments with broadly noninferential support such that (i) this construal reflects the way the notion is used in philosophical practice, (ii) it is plausible that philosophy relies significantly on intuitions in this sense, and (iii) this reliance raises significant epistemological and methodological worries.” Cf. Cappelen (2014).
} 


\subsection{Some intuitions do have the power to rationally persuade other philosophers!}

The second objection states that some intuitions do have the power to rationally persuade other professional analytic philosophers. For example, some might think that the so-called "Gettier intuition" manages to do just that. The "Gettier intuition" is the intuitive judgment that a subject in a Gettier case doesn't know that $p$. The fact that Gettier's (1963) paper has generated an enormous literature in the field of epistemology (Shope 1983) is evidence that the "Gettier intuition" does have the power to rationally persuade other philosophers, especially epistemologists, or so it might be argued.

Doing justice to the "Gettier intuition" is clearly beyond the scope of this paper. As mentioned above, the literature on the so-called "Gettier problem" is enormous (see, e.g., Borges et al., 2017). For present purposes, I hope it is enough to make the following points in reply. First, this objection is borderline question-begging. I provided an argument whose conclusion is that appeals to intuition in Analytic Philosophy are not compelling arguments, but this objection amounts to retorting, "Yes, they are." (Recall Monty Python's argument clinic mentioned in Section 2.) For an appeal to intuition is always an appeal to someone's intuition, which means that, if one has the intuition that a subject in a Gettier case doesn't know that $p$, one is appealing to one's personal and private (or nontransparent) evidence.

In other words, we must distinguish between an intuition as a personal, private, firstperson mental state and the content of that mental state. For example, the content of the "Gettier intuition" is $\langle S$ doesn't know that $p$ in a Gettier case $>$. The reason we are supposed to believe this content is that the content is supposed to be intuitive. That is, Gettier cases are supposed to derive their power of rational persuasion from the fact that the content of the "Gettier intuition," namely, $\langle S$ doesn't know that $p$ in a Gettier case $>$, is supposed to be intuitive. An intuition with content $p$ has the power to rationally persuade one only if one finds $p$ intuitive, i.e., only if it seems to one that $p$. But, again, this makes intuitions inherently personal and private (or nontransparent), not public (or transparent), and thus not the sort of thing that can have the power to rationally persuade professional analytic philosophers other than oneself. The fact that you have the intuition that $S$ doesn't know that $p$ in a Gettier case does nothing at all to rationally persuade $m e$ that $S$ doesn't know that $p$ in a Gettier case unless I also find that content, namely, $<S$ doesn't know that $p$ in a Gettier case $>$, intuitive. In an academic community of scholars, as Analytic Philosophy is supposed to be, the so-called "Gettier intuition" cannot serve as a neutral arbiter of epistemological debates concerning the nature knowledge.

Even if the intuitions of different professional analytic philosophers have the same content, it is still the case that they would be appealing to different pieces of evidence to support that content. I might have an intuition whose content is $\langle S$ doesn't know that $p$ in a Gettier case $>$ and you might have an intuition whose content is $\langle S$ doesn't know that $p$ in a Gettier case $\rangle$ as well. But your intuition is yours and my intuition is mine; they are distinct personal, private, first-person mental states, even if the content, namely, $\langle S$ doesn't know that $p$ in a Gettier case $>$, is the same. When I appeal to intuition, I use my intuition that $S$ doesn't know that $p$ in a Gettier case as evidence for the claim that $S$ doesn't know that $p$ in a Gettier case. When you appeal to intuition, you use your intuition that $S$ doesn't know that $p$ in a Gettier case as evidence for $S$ doesn't know that $p$ in a Gettier case. Although we are both arguing that $S$ doesn't know that $p$ in a Gettier case by appeal to intuition, our evidence is not the same: my evidence is my intuition that $S$ doesn't know that $p$ in a Gettier case, whereas your evidence is your intuition that $S$ 
doesn't know that $p$ in a Gettier case. Clearly, your intuition that $S$ doesn't know that $p$ in a Gettier case and my intuition that $S$ doesn't know that $p$ in a Gettier case are distinct because the former is in your head, whereas the latter is in my head. This means that we are making different arguments effectively. Your argument is "It seems to me that $S$ doesn't know that $p$ in a Gettier case; therefore, $S$ doesn't know that $p$ in a Gettier case," whereas my argument is "It seems to me that $S$ doesn't know that $p$ in a Gettier case; therefore, $S$ doesn't know that $p$ in a Gettier case." I cannot be rationally persuaded by your argument because you are the only one who has access to the evidence appealed to in the premise of your argument (it is your intuition). Similarly, you cannot be rationally persuaded by my argument because I am the only one who has access to the evidence appealed to in the premise of my argument (it is my intuition). Insofar as we are both members of an academic community of professional analytic philosophers, whose goal is rational persuasion of its members by means of reasons or evidence, as long as we appeal to intuition, we would fail to attain our communal goal.

Indeed, if professional analytic philosophers use intuitions as if appeals to intuition were compelling arguments for and/or against philosophical theses, although intuitions have no power of rational persuasion over other professional analytic philosophers, then this would explain why philosophical questions appear to be enduring, philosophical debates appear to be intractable, and agreement on philosophical issues appears to be practically impossible. As van Inwagen (2004, p. 332) writes:

Disagreement in philosophy is pervasive and irresoluble. There is almost no thesis in philosophy about which philosophers agree. If there is any philosophical thesis that all or most philosophers affirm, it is a negative thesis: that formalism is not the right philosophy of mathematics, for example, or that knowledge is not (simply) justified, true belief.

According to Chalmers (2015, p. 25), the appearance of pervasive and irresoluble disagreement in Analytic Philosophy has to do with the method used by professional analytic philosophers. That is, there is more disagreement and "less convergence in philosophy [than in science] because the philosophical method has less power to compel agreement" (Chalmers 2015, p. 25). Now, if my overall argument is sound, then Chalmers' explanation for the lack of "collective convergence to the truth" (Chalmers 2015, p. 4) in Analytic Philosophy is spot on. To this explanation, we can add that this lack of "power to compel agreement" has to do with the fact that professional analytic philosophers appeal to intuition and that intuitions have no "power to compel agreement." In other words, if a central method of philosophical argumentation is appealing to intuitions, but appeals to intuition are not compelling arguments because intuitions have no power of rational persuasion over other professional analytic philosophers, then it is not surprising that "there is less convergence in philosophy than in science" (Chalmers 2015, p. 27). For this reason, as long as professional analytic philosophers keep appealing to intuitions as if they were the sort of evidence for and/or against philosophical theses that has power to compel agreement, there would be less collective convergence to the truth in Analytic Philosophy than in science. As Railton (1985, p. 764) writes, "objective inquiry uses procedures that are intersubjective and independent of particular individuals or circumstances — for example, [...] it makes no essential use of introspective or subjectively privileged evidence in theory assessment." Insofar as intuitions are "subjectively privileged evidence," and professional 
analytic philosophers appeal to intuitions in philosophical practice, Analytic Philosophy cannot be the objective field of inquiry it must be. ${ }^{22}$

\subsection{Like perception, intuition is a source of evidence, too!}

The third objection states that my overall argument, if sound, entails not only that appeals to intuition are not compelling arguments but also that appeals to sense perception are not compelling arguments. In other words, if sense perception is a source of compelling evidence, then intuition is a source of compelling evidence, too, for the two are analogous in epistemically relevant respects.

First, it is important to remember that the conclusion of my overall argument is (7), namely, that intuitions are not the sort of evidence for and/or against philosophical theses that has the power to rationally persuade other professional analytic philosophers. In other words, appeals to intuition are not the sort of arguments that can help professional analytic philosophers attain the goal of Analytic Philosophy, which is rational persuasion by means of arguments. This leaves open the possibility that intuitions could serve as compelling evidence outside of Analytic Philosophy. In a non-academic, non-scholarly setting, if you tell me that you see that $p$, I might take that as sufficient evidence for believing that $p$. Similarly, if you tell me that you intuit that $p$ in a non-academic, non-scholarly setting, I might also take that as sufficient evidence for believing that $p$. When it comes to academic disciplines and scholarly fields of inquiry, however, that you see or intuit that $p$ should not be construed as sufficient evidence for other researchers and scholars in the field for accepting $p$. Surely, in academic disciplines and professional fields of inquiry, standards of evidence should be more rigorous than that. Again, "objective inquiry uses procedures that are intersubjective and independent of particular individuals or circumstances" (Railton 1985, p. 764).

Second, if the objection is that intuitions are private mental states and perceptions are private mental states, and thus perceptions are not compelling evidence because intuitions are not compelling evidence, then this objection relies on an invalid argument. From the fact that two things, $X$ and $Y$, share a property in common, it doesn't necessarily follow that $X$ and $Y$ also share other properties in common. For example, from the fact that electrons and protons are both subatomic particles, it doesn't necessarily follow that both are affected by the strong force. For this reason, this objection, according to which my overall argument, if sound, entails not only that appeals to intuition are not compelling arguments but also that appeals to sense perception are not compelling arguments, presupposes that intuition and sense perception are analogous in epistemically relevant respects. For only if there is an epistemically relevant analogy between intuition and perception does it follow that perception is not a source of compelling evidence from the fact that intuition is not a source of compelling evidence. The question, then, is whether the supposed analogy between intuition and perception is a strong or a weak analogy. If it is a strong analogy, then the objection is a strong objection against my overall argument. If it is a weak analogy, then the objection is a weak objection against my overall argument.

\footnotetext{
22 Recall the point about "Evidence Neutrality" from Section 4. Insofar as the academic community of professional analytic philosophers is concerned, common knowledge as to whether any given intuitive judgment constitutes evidence for and/or against a philosophical thesis is rarely, if ever, achieved. If my argument is sound, this fact about Analytic Philosophy can be explained: professional analytic philosophers use intuitions as evidence, but intuitions are not the sort of thing that has the power to rationally compel agreement among other professional analytic philosophers because intuitions are not public (or transparent) evidence.
} 
Now, some philosophers think that intellectual intuition is analogous to sense perception in epistemically relevant respects. For example, according to Chudnoff (2013a, p. 364):

The structural parallels between [Intuitive Knowledge] and [Perceptual Knowledge] should be obvious. The differences are that intuitive appearance replaces perceptual appearance and intellectual awareness replaces sensory awareness (emphasis added).

Notice that the perception-intuition analogy is not argued for, but rather is taken as obvious. If we have learned anything from experimental philosophy, however, it is that what may seem obvious to some philosophers may not seem obvious to other philosophers or to nonphilosophers. ${ }^{23}$ The question, then, is whether there are good reasons to accept the alleged analogy between sense perception and intellectual intuition. If sense perception and intellectual intuition are not analogous in epistemically relevant respects, then it does not follow that appeals to sense perception are not compelling arguments from the claim that appeals to intuition are not compelling arguments. To the best of my knowledge, there are no arguments for the perceptionintuition analogy in the extant literature on metaphilosophy and philosophical methodology. As we have seen, it is taken for granted that sense perception and intellectual intuition are analogous in epistemically relevant respects, and then it is argued that, like sense perception, intellectual intuition is a source of evidence. For instance, like Chudnoff (2013a), Hales (2012, p. 180) claims that "if we regard sense perception as a mental faculty that (in general) delivers justified beliefs, then we should treat intuition in the same manner." But why should we? Why think that sense perception and intellectual intuition should be treated in the same manner? In the absence of good reasons to think that they are analogous in epistemically relevant respects, it does not follow that appeals to sense perception are not compelling arguments from the claim that appeals to intuition are not compelling arguments. In other words, my overall argument would have the consequence that appeals to sense perception are not compelling arguments, which might seem absurd to some, only if sense perception and intellectual intuition are analogous in epistemically relevant ways. There are no good reasons to think that they are analogous in epistemically relevant ways. Therefore, it is not the case that my overall argument entails that appeals to sense perception are not compelling arguments. ${ }^{24}$

In fact, there are good reasons to think that sense perception and intellectual intuition are not analogous in epistemically relevant respects. That is, there are epistemically relevant dissimilarities between intuition and perception, which means that the analogy between the two is neither obvious nor strong. While both sense perceptions and intellectual intuitions are mental states, the latter are private in two respects that the former are not. The first respect in which intuition is private, but perception is not, has to do with the supposed "faculty of intuition." That is, we have a decent understanding of sensory perception, especially, visual perception (see, e.g., Snowden et al. 2012), whereas the so-called "faculty of intuition" (Hales 2012) is a totally

\footnotetext{
${ }^{23}$ See Sytsma and Livengood (2016, pp. 51-59) on the "negative program" in experimental philosophy. To argue that perception and intuition are analogous because it seems (to one) that they are is not going to convince anyone who doubts the perception-intuition analogy itself, for this argument presupposes what it purports to show, namely, that, just like perception, intuition is also a source of evidence. See, e.g., Huemer (2001, p. 112): " $S$ might have a perceptual experience or an intuition representing that $P$. [...] Is $S$ now justified in believing that $P$ ? It seems to me that he is" (emphasis added).

${ }^{24}$ See also Pust's (2019) Stanford Encyclopedia of Philosophy entry on "intuition," where he writes that an "analogy with perception is helpful" to illustrating important features of intuition but does not give an argument for the analogy.
} 
mysterious thing. As Symons (2008, p. 67) writes, "While intuition is widely regarded as a source of belief, the manner in which intuition plays this role is obscure." This is an epistemically relevant dissimilarity between sense perception and intellectual intuition because, in order to know whether a method of inquiry is reliable, we must have a good idea of how it is supposed to work. As a method of philosophical inquiry, however, appeals to intuition cannot be said to be reliable without having some idea of how the mysterious "faculty of intuition" is supposed to work. Of course, it would be question-begging to retort that the "faculty of intuition" is supposed to work in the same way that the visual cortex does, since the question at hand is whether the two are analogues in epistemically relevant respects.

The second respect in which intuition is private, but perception is not, has to do with the supposed content of intuitions. As I have argued in Section 5, the content of intuitions is inherently personal and private (or nontransparent), not public (or transparent). I might have an intuition whose content is $\langle S$ doesn't know that $p$ in a Gettier case $>$ and you might have an intuition whose content is $\langle S$ doesn't know that $p$ in a Gettier case $>$ as well. But your intuition is yours and my intuition is mine; they are distinct personal, private, first-person mental states, even if the content, namely, $\langle S$ doesn't know that $p$ in a Gettier case $>$, is the same. When I appeal to intuition, I use my intuition that $S$ doesn't know that $p$ in a Gettier case as evidence for the claim that $S$ doesn't know that $p$ in a Gettier case. When you appeal to intuition, you use your intuition that $S$ doesn't know that $p$ in a Gettier case as evidence for $S$ doesn't know that $p$ in a Gettier case. Although we are both arguing that $S$ doesn't know that $p$ in a Gettier case by appeal to intuition, our evidence is not the same: my evidence is my intuition that $S$ doesn't know that $p$ in a Gettier case, whereas your evidence is your intuition that $S$ doesn't know that $p$ in a Gettier case. Clearly, your intuition that $S$ doesn't know that $p$ in a Gettier case and my intuition that $S$ doesn't know that $p$ in a Gettier case are distinct because the former is in your head, whereas the latter is in my head. Admittedly, there is a longstanding debate in philosophy as to whether sense perception (particularly, visual perception) gives us direct access to objects in the external world. But some philosophers do think that we perceive (or see) objects in the external world directly. If those philosophers are right about that, then the objects of sense perception are public (or transparent) in a way that the objects of intellectual intuition are not. For, unlike the objects of sense perception, the objects of intellectual intuition are supposed to be abstract objects, which can only be accessed by intuition (Chudnoff 2013a, p. 360).

To sum up, then, intellectual intuition is private (or nontransparent) in two respects. First, the supposed "faculty of intuition" is private (or nontransparent) in the sense that it is totally mysterious to us, whereas our faculty of visual perception is not. We have no idea how the socalled "faculty of intuition" is supposed to work. Second, the contents of intuition are private (or nontransparent) in the sense that the objects of intellectual intuitions are supposed to be abstract and accessible only to the person who is intuiting them, whereas the objects of sense perception are concrete and in principle accessible to all visual perceivers.

Another epistemically relevant dissimilarity between sense perception, particularly visual perception, and intellectual intuition is the following: like knowing that $p$, the perceptual state seeing that $p$ is factive (French 2013). ${ }^{25}$ That is, if $S$ sees that $p$, then $p$ is the case. If $p$ is not the case, then $S$ did not really see that $p$; it merely seemed to $S$ as if she is seeing that $p$ (as in the

\footnotetext{
${ }^{25}$ See Pritchard (2012), Part One.
} 
case of hallucinations). Intuition, however, is not factive. That is, even if $S$ intuits that $p$ or it seems to $S$ that $p, p$ could still be false. Now, compare the following argument schemes:

Appeal to Intellectual Intuition

$S$ intuits that $p$.

$\therefore p$.
Appeal to Visual Perception

$S$ sees that $p$.

$\therefore p$.

As far as appeals to visual perception are concerned, the truth of the premise guarantees the truth of the conclusion, given that seeing that $p$ is factive. As far as appeals to intellectual intuition are concerned, however, the truth of the premise does not guarantee the truth of the conclusion, given that intuiting that $p$ is not factive.

To this, it might be objected that seeing that $p$ may be factive, but visually perceiving that $p$ is not. However, those who defend the evidential role of intuition in Analytic Philosophy would agree that visually perceiving that $p$ is veridical. For example, according to Chudnoff (2013a, p. 361), "Perception is a success state: perceiving is veridical and non-hallucinatory." Therefore, both seeing that $p$ and visually perceiving that $p$ provide compelling evidence for $p$ insofar as the former is factive and the latter is veridical. Unlike perception, however, intuition is not a success state, for intuiting that $p$ is neither factive nor veridical. Therefore, intuiting that $p$ does not provide compelling evidence for $p$.

For these reasons, appeals to intuition are inherently problematic as a philosophical methodology or style of argument in Analytic Philosophy. To establish the trustworthiness or reliability of a method of inquiry, one must be able to test the outputs of the method in independent ways. For example, to establish the reliability of the telescope as a trustworthy instrument of celestial observation, Galileo tested it by observing terrestrial objects first, such as ships coming into a harbor, and then comparing what he observed through the telescope to what he can observe independently of the instrument (Kitcher 2001). As far as appeals to intuition are concerned, there is no way to test the outputs of this method independently of intuition, since those outputs are supposed to be accessible only by intuition. This means that there is no independent way to establish the reliability of appeals to intuition as a trustworthy or reliable method of philosophical inquiry. For, if the objects of intuition are abstract objects, which can only be accessed by intuition, as Chudnoff (2013a, p. 360) argues, then there is no way to access the alleged objects of intuition other than by intuition itself. Since gaining "access to the target that is independent of the instrument or procedure to be calibrated" is an "invariable requirement" for establishing the trustworthiness or reliability of an instrument or procedure (Cummins 1998, p. 117), it follows that the trustworthiness or reliability of intuition as a method of philosophical inquiry cannot be established. In other words, "philosophical intuition could be calibrated, but only on the assumption that there is some nonintuitive access to its target" (Cummins 1998, p. 117). In the case of visual perception, I can gain access to the objects of visual perception that is independent of my sense of vision by using optical instruments, such as autocollimators, cameras, spectrometers, telescopes, etc. In the case of intuition, however, there is no way to gain access to the objects of intuition by any means other than intuition itself. There is no non-intuitive access to the targets of philosophical intuition because those targets are supposed to be abstract objects. Therefore, unlike sense perception, intellectual intuition cannot be calibrated. 
Since there are significant, epistemically relevant dissimilarities between sense perception and intellectual intuition, as we have seen, the alleged analogy between the two is weak. If it is not the case that sense perception and intellectual intuition are analogous in epistemically relevant respects, then it is not the case that my overall argument entails the allegedly absurd consequence that appeals to sense perception are not compelling arguments. ${ }^{26}$

\subsection{If not intuitions, then what?}

Some might object that intuitions are indispensable to philosophical argumentation. That is, if professional analytic philosophers cannot appeal to intuitions as evidence for and/or against philosophical theses, what else is there? Ichikawa (2013, p. 116) discusses - though does not endorse - an argument along these lines, which he calls the "What Else?" argument.

To see the problem with the "What Else?" argument, suppose that professional analytic philosophers could only argue by appeal to pity. By stipulation, no other method or style of argument is available to professional analytic philosophers. Every argument in Analytic Philosophy would run along the following lines:

If you don't agree with me that $p$, my reputation will be ruined. I will probably lose my job and my family will starve. Therefore, you must agree that $p$ (adapted from Hurley 2016, p. 68).

Even if appeal to pity were the only method or style of argument available to professional analytic philosophers, it would still be a bad method or style of argument. The fact that it is the only method or style of argument that professional analytic philosophers have does not change the fact that it is a bad way to argue. Similarly, even if intuitions were the only thing professional analytic philosophers could appeal to in their arguments, it would not make a difference to whether or not appealing to intuition is a good way to argue. In other words, it could still be the case that intuitions are not the sort of thing that can rationally persuade other professional analytic philosophers, even if it were the case that professional analytic philosophers can only argue by appeals to intuition.

Furthermore, it is not in fact true that intuitions are the only thing professional analytic philosophers can appeal to in their arguments. According to Dutilh Novaes (2012, p. 255), "not only is there room for distinct methodological approaches in philosophy but also that they should be combined in one and the same investigation" (emphasis in original). In addition to what she calls "traditional methods," i.e., conceptual (a priori) reflection and analysis, Dutilh Novaes (2012, pp. 250-254) identifies the following methods that are available to professional analytic philosophers:

1. Formal methods: the application of mathematical and logical formalisms to philosophical questions (e.g., formal epistemology and formal semantics);

2. Historical methods: the use of the history of philosophy to understand philosophically relevant concepts (e.g., historical epistemology and HPS);

3. Empirical methods: informing philosophical discussions with empirical results from the sciences (e.g., moral psychology and experimental philosophy).

\footnotetext{
${ }^{26}$ Mizrahi (2014, p. 193) argues that "making intuitive judgments in response to intuition pumps is as unreliable as making perceptual judgments in response to illusions."
} 
Unlike intuitions, logical formalisms, historical documents, and empirical results are public (or transparent). As such, they have the power to rationally persuade other professional analytic philosophers. In other words, appeals to intuition are not compelling arguments because intuitions are not the sort of evidence for and/or against philosophical theses that has the power to rationally persuade other professional analytic philosophers, whereas appeals to logical formalisms, historical documents, and empirical results can be compelling arguments because logical formalisms, historical documents, and empirical results are the sort of evidence that has the power to rationally persuade other professional analytic philosophers. When I argue that $p$ by appeal to intuition, my evidence is my own intuition that $p$, whereas when you argue that $p$ by appeal to intuition, your evidence is your own intuition that $p$. By contrast, when we argue that $p$ by appeal to experimental results, for example, you and I are appealing to the same empirical evidence.

\section{Conclusion}

In this paper, I argued that appeals to intuition in Analytic Philosophy are not compelling arguments for and/or against philosophical theses because intuitions are not the sort of thing that has the power to rationally persuade other professional analytic philosophers. This conclusion follows from reasonable premises about the goal of Analytic Philosophy, which is rational persuasion by means of arguments, and the requirement that evidence for and/or against philosophical theses be public (or transparent) in order to have the power to rationally persuade professional analytic philosophers other than oneself. Since intuitions are not public (or transparent) evidence, it follows that appeals to intuition are not compelling arguments for and/or against philosophical theses because they lack the power to rationally persuade other professional analytic philosophers. If this is correct, then appeals to intuition to professional analytic philosophers are like Jedi mind tricks to Jabba the Hutt: they do not work.

\section{Acknowledgments}

I am very grateful to two anonymous reviewers for Axiomathes for their helpful comments on an earlier draft of this paper.

\section{Declarations}

Funding: not applicable

Conflict of interest: the author(s) declare no conflicts of interest

Availability of data: not applicable

Code availability: not applicable

\section{References}

Achinstein, P. (2001). The Book of Evidence. New York: Oxford University Press.

Andow, J. (2016). Intuitions. Analysis 76 (2):232-246.

Anscombe, G.E.M. (1966). A Note on Mr. Bennett. Analysis 26 (6):208. 
Arvan, M. (2017). Experimental Philosophy and the Fate of the Philosopher's Armchair. Metascience 26 (1):95-98.

Ashton, Z., and Mizrahi, M. (2018). Intuition Talk is Not Methodologically Cheap: Empirically Testing the "Received Wisdom" about Armchair Philosophy. Erkenntnis 83 (3):595-612.

Bach, K. (1984). Default Reasoning: Jumping to Conclusions and Knowing When to Think Twice. Pacific Philosophical Quarterly 65 (1):37-58.

Baz, A. (2016a). Recent Attempts to Defend the Philosophical Method of Cases and the Linguistic Turn. Philosophy and Phenomenological Research 92 (1):105-130.

Baz, A. (2016b). On Going Nowhere with Our Words: New Skepticism about the Philosophical Method of Cases. Philosophical Psychology 29 (1):64-83.

Beaney, M. (2013). What is Analytic Philosophy? In M. Beaney (ed.), The Oxford Handbook of the History of Analytic Philosophy (3-29). Oxford: Oxford University Press.

Bermejo-Luque, L. (2011). Giving Reasons: A Linguistic-Pragmatic Approach to Argumentation Theory. Dordrecht: Springer.

Block, N. (2014). The Defective Armchair: A Reply to Tye. Thought: A Journal of Philosophy 3 (2):159-165.

Booth, A.R. and Rowbottom, D.P. Eds. (2014). Intuitions. New York: Oxford University Press.

Borges, R., de Almeida, C., and Klein, P. (2017). Introduction. In R. Borges, C. de Almeida, and P. Klein (eds.), Explaining Knowledge: New Essays on the Gettier Problem (1-11). New York: Oxford University Press.

Bruce, M., and Barbone, S. (2011). Introduction: Show Me the Arguments. In M. Bruce and S. Barbone (eds.), Just the Arguments: 100 of the Most Important Arguments in Western Philosophy (1-6). Malden, MA: Wiley Blackwell.

Cappelen, H. (2012). Philosophy without Intuitions. Oxford: Oxford University Press.

Cappelen, H. (2014). Replies to Weatherson, Chalmers, Weinberg, and Bengson. Philosophical Studies 171 (3):577-600.

Chalmers, D. (2014). Intuitions in Philosophy: A Minimal Defense. Philosophical Studies 171 (3):535-544.

Chalmers, D. (2015). Why Isn't There More Progress in Philosophy? Philosophy 90 (1):3-31.

Chudnoff, E. (2013a). Intuitive Knowledge. Philosophical Studies 162 (2):359-378.

Chudnoff, E. (2013b). Awareness of Abstract Objects. Noûs 47 (4):706-726.

Climenhaga, N. (2018). Intuitions are Used as Evidence in Philosophy. Mind 127 (505):69-104.

Cohen, D.H. (2004). Arguments and Metaphors in Philosophy. New York: University Press of America. 
Cohnitz, D. and Haukioja, J. (2015). Intuitions in Philosophical Semantics. Erkenntnis 80 (3):617-641.

Conee, E. and Feldman, R. (2004). Evidentialism. Oxford: Oxford University Press.

Cummins, R. (1998). Reflection on Reflective Equilibrium. In M.R. DePaul and W. Ramsey (eds.), Rethinking Intuition: The Psychology of Intuition and Its Role in Philosophical Inquiry (113-128). Lanham, MD: Rowman \& Littlefield.

Dainton, B., and Robinson, H. (2014). Preface. In B. Dainton and H. Robinson (eds.), The Bloomsbury Companion to Analytic Philosophy (x-xv). London: Bloomsbury.

De Cruz, H. (2015). Where Philosophical Intuitions Come From. Australasian Journal of Philosophy 93 (2):233-249.

Deutsch, M. (2015). The Myth of the Intuitive: Experimental Philosophy and Philosophical Method. Cambridge, MA: MIT Press.

Devitt, M. (2015). Relying on Intuitions: Where Cappelen and Deutsch Go Wrong. Inquiry 58 (7-8):669-699.

Dutilh Novaes, C. (2012). Formal Languages in Logic: A Philosophical and Cognitive Analysis. New York: Cambridge University Press.

Dutilh Novaes, C. (2015). A Dialogical, Multi-Agent Account of the Normativity of Logic. Dialectica 69 (4):587-609.

French, C. (2013). Perceptual Experience and Seeing that P. Synthese 190 (10):1735-1751.

Govier, T. and Hoaglund, J. (1999). The Philosophy of Argument. Newport, VA: Vale Press.

Govier, T. (2010). A Practical Study of Argument. Seventh Edition. Belmont, CA: Wadsworth, Cengage Learning.

Hales, S.D. (2012). The Faculty of Intuition. Analytic Philosophy 53 (2):180-207.

Hannon, M. (2018). Intuitions, Reflective Judgments, and Experimental Philosophy. Synthese 195(9):4147-4168.

Harrell, M. (2016). What is the Argument? An Introduction to Philosophical Argument and Analysis. Cambridge, MA: MIT Press.

Huemer, M. (2001). Skepticism and the Veil of Perception. Lanham, MD: Rowman \& Littlefield.

Huemer, M. (2007). Compassionate phenomenal conservatism. Philosophy and Phenomenological Research 74 (1):30-55.

Hurley, P.J. (2016). Logic: The Essentials. Stamford, CT: Cengage Learning.

Ichikawa, J.J. (2013). Review of Philosophy without Intuitions. International Journal of Philosophical Studies 21 (1):111-131.

Jackson, F. (1982). Epiphenomenal Qualia. Philosophical Quarterly 32: 127-136 
Johnson, R.H. (2000). Manifest Rationality: A Pragmatic Theory of Argument. Mahwah, NJ: Lawrence Erlbaum.

Kelly, T. (2016). Evidence. In E.N. Zalta (ed.), The Stanford Encyclopedia of Philosophy (Winter 2016 Edition). https://plato.stanford.edu/archives/win2016/entries/evidence/.

Kithcer, P. (2001). Real Realism: The Galilean Strategy. The Philosophical Review 110 (2):151197.

Lacewing, M. (2014). Philosophy for AS: Epistemology and Philosophy of Religion. London: Routledge.

Levy, N. (2013). Intuitions and experimental philosophy: Comfortable bedfellow. In M.C. Haug (ed.), Philosophical Methodology: The Armchair or the Laboratory? (381-415). New York:

Routledge.

Lycan, W.G. (2006). On the Gettier Problem Problem. In S. Hetherington (ed.), Epistemology Futures (148-168). New York: Oxford University Press.

Machery, E. (2017). Philosophy Within Its Proper Bounds. New York: Oxford University Press. Martin, R.M. (2017). For the Sake of Argument: How to Do Philosophy. Ontario: Broadview Press.

Mitova, N. (2017). Believable Evidence. New York: Cambridge University Press.

Mizrahi, M. (2014). Does the Method of Cases Rest on a Mistake? Review of Philosophy and Psychology 5 (2):183-197.

Mizrahi, M. (2015). Don't Believe the Hype: Why Should Philosophical Theories Yield to Intuitions? Teorema: Revista Internacional de Filosofía 34 (3): 141-158.

Molyneux, B. (2014). New Arguments that Philosophers Don't Treat Intuitions as Evidence. Metaphilosophy 45 (3):441-461.

Moretti, L. (2015). Phenomenal conservatism. Analysis 75 (2):296-309.

Musgrave, A. (2012). Getting Over Gettier. In J. Maclaurin (ed.), Rationis Defensor: Essays in Honour of Colin Cheyne (3-10). Dordrecht: Springer.

Nagel, J. (2012). Intuitions and Experiments: A Defense of the Case Method in Epistemology. Philosophy and Phenomenological Research 85 (3):495-527.

Nagel, J. (2013). Defending the Evidential Value of Epistemic Intuitions: A Reply to Stich. Philosophy and Phenomenological Research 87 (1):179-199.

Nado, J. (2016a). Experimental Philosophy 2.0. Thought: A Journal of Philosophy 5 (3):159-168.

Nado, J. (2016b). The Intuition Deniers. Philosophical Studies 173 (3):781-800.

Nado, J. Ed. (2016c). Advances in Experimental Philosophy and Philosophical Methodology. London: Bloomsbury.

Peirce, C.S. (1877). The Fixation of Belief. Popular Science Monthly 12: 1-15. 
Prinz, J. (2006). The Emotional Basis of Moral Judgments. Philosophical Explorations 9 (1):2943.

Pritchard, D. (2012). Epistemological Disjunctivism. Oxford: Oxford University Press.

Pust, J. (2019). Intuition. In E.N. Zalta (ed.), The Stanford Encyclopedia of Philosophy (Summer 2019 Edition). https://plato.stanford.edu/archives/sum2019/entries/intuition/.

Railton, P. (1985). Marx and the Objectivity of Science. In R. Boyd, P. Gasper, and J.D. Trout (eds.), The Philosophy of Science (763-773). Cambridge, MA: MIT Press.

Ramsey, W. (2019). Intuitions as Evidence Facilitators. Metaphilosophy 50 (1-2):76-99.

Schmidt-Petri, C. (2003). Is Gettier's First Example Flawed? In W. Löffler and P. Weingartner (eds.), Knowledge and Belief (317-319). ALWS.

Schwitzgebel, E., Huang, L. T., Higgins, A., and Gonzalez-Cabrera, I. (2018). The Insularity of Anglophone Philosophy: Quantitative Analyses. Philosophical Papers 47 (1): 21-48.

Shope, R.K. (1983). The Analysis of Knowledge: A Decade of Research. Princeton, NJ:

Princeton University Press.

Snowden, S., Thompson, P., and Troscianko, T. (2012). Basic Vision: An Introduction to Visual Perception. Revised Edition. Oxford: Oxford University Press.

Soames, S. (2003). Introduction to the Two Volumes. In S. Soames (ed.), Philosophical Analysis in the Twentieth Century: Volume 1 The Dawn of Analysis (xi-xix). Cambridge, MA: MIT Press.

Starmans, C. and Friedman, O. (2012). The Folk Conception of Knowledge. Cognition 124 (3):272-283.

Stich, S. (2013). Do Different Groups have Different Epistemic Intuitions? A Reply to Jennifer Nagel. Philosophy and Phenomenological Research 87 (1):151-178.

Suhler, C. (2019). Why the Method of Cases Doesn't Work. Review of Philosophy and Psychology 10 (4): 825-847.

Symons, J. (2008). Intuition and Philosophical Methodology. Axiomathes 18 (1):67-89.

Sytsma, J. and Livengood, J. (2016). The Theory and Practice of Experimental Philosophy. Peterborough: Broadview Press.

Trafford, J. (2017). Meaning in Dialogue: An Interactive Approach to Logic and Reasoning. Springer.

Taylor, C. (1995). Philosophical Arguments. Cambridge, MA: Harvard University Press.

Van Inwagen, P. (2004). Freedom to Break the Laws. Midwest Studies in Philosophy 28 (1):334350 .

Verene, D.P. (1989). Philosophy, Argument, and Narration. Philosophy and Rhetoric 22 (2):141144.

Walton, D. (2005). Argumentation Methods for Artificial Intelligence in Law. Berlin: Springer. 
Williamson, T. (2007). The Philosophy of Philosophy. Malden, MA: Blackwell Publishing.

Wittgenstein, L. (1969). On Certainty. Trans. D. Paul and G.E.M. Anscombe. New York: Harper \& Row.

Wysocki, T. (2017). Arguments over Intuitions? Review of Philosophy and Psychology 8 (2):477-499. 